\title{
DIGITALCOMMONS
}

$@$ WAYNESTATE-

Wayne State University

Civil and Environmental Engineering Faculty

Research Publications

Civil and Environmental Engineering

3-28-2019

\section{Reliability-Based Shear Rating of Prestressed Concrete Bridge Girders Considering Capacity Adjustment Factor}

\author{
Alaa I. Chehab \\ Nesai/Nasr Consulting Engineers, Inc., alaa.chehab@wayne.edu \\ Christopher D. Eamon \\ Wayne State University, eamon@eng.wayne.edu
}

Follow this and additional works at: https://digitalcommons.wayne.edu/ce_eng_frp

Part of the Civil Engineering Commons, Construction Engineering and Management Commons, Structural Engineering Commons, and the Transportation Engineering Commons

\section{Recommended Citation}

Chehab, A. I. and Eamon, C. D. 2019. "Reliability-based shear rating of prestressed concrete bridge girders considering capacity adjustment factor." J. Risk Uncertainty Eng. Syst., Part A: Civ. Eng. 5 (2): 04019006. https://doi.org/10.1061/AJRUA6.0001009.

This Article is brought to you for free and open access by the Civil and Environmental Engineering at DigitalCommons@WayneState. It has been accepted for inclusion in Civil and Environmental Engineering Faculty Research Publications by an authorized administrator of DigitalCommons@WayneState. 


\section{Abstract}

11 In this study, the reliability of prestressed concrete (PC) bridge girders in the shear rating process

12 is quantified, where the use of a simple procedure to enhance the accuracy of shear capacity

13 evaluation for rating is evaluated. It was found that the approximate methods used in code-based

14 procedures to develop shear resistance used for reliability calibration of the AASHTO Bridge

15 Design Specifications and the Manual for Bridge Evaluation result in larger discrepancies in

16 reliability than previously assumed, as well as substantially conservative shear capacity evaluation

17 in most cases. To examine the effects of using a more accurate shear rating process, a selection of

18 typical PC bridge girders designed and rated for Michigan legal loads is considered as an example.

19 For the example girders, use of existing methods resulted in some reliability indices below the

20 required levels. However, use of the more accurate procedure resulted in shear reliability indices

21 that met the target reliability index, thus preventing unnecessary traffic restrictions as well as

22 avoiding potentially rating structures unconservatively.

24 Author keywords: prestressed concrete; shear; bridge structures. 


\section{Introduction}

26 Bridge load rating is required by the US Department of Transportation (DOT) to assure that bridge

27 structures within each state inventory are sufficiently safe for vehicular traffic. Specific bridge

28 rating procedures are specified in the Manual for Bridge Evaluation (MBE) (AASHTO 2018),

29 where rating for design, legal, and permit loads is discussed. Generally, it is desired by the DOTs

30 to limit bridge posting as much as possible, as restrictions prevent the general public, as well as

31 commercial vehicles, from fully utilizing the transportation network. Typically, the design load

32 rating evaluates the ability of the bridge to carry the HL-93 design load specified in the American

33 Association of State Highway and Transportation Officials Load and Resistance Factor Design

34 Specifications (AASHTO LRFD 2017), and is used to complete the Federal inventory rating. The

35 design load is also used to evaluate the bridge at the Federal operating level, where capacity

36 associated with a lower level of reliability is assessed. Structures found to be inadequate for design-

37 based load rating must be further evaluated considering legal load rating, to determine if traffic

38 restriction is required. In the rating process, to ensure target levels of structural safety, it is

39 necessary to use accurate procedures for evaluating bridge capacity. Although various failure

40 modes may be of interest, flexural and shear strength-based limit states are often of greatest

41 concern for rating typical highway bridge girders. The specific concern of this study is girder

42 shear capacity. While the analysis procedures given in AASHTO LRFD may be expected to

43 generally well-predict flexural capacity, it has been shown that significant inaccuracies exist using

44 current methods to model shear behavior (Llanos et al. 2009; Ross et al. 2011; Wilder et al. 2015,

45 Chehab and Eamon 2018, Chehab et al. 2018). Although generally conservative in most cases,

46 inaccuracies in code-based analysis methods create the undesirable situation where shear capacity

47 is significantly under-reported, potentially resulting in unnecessary traffic restrictions. A more 
troublesome result is that, in a smaller number of cases, bridges may be over-rated in capacity

49 (Chehab and Eamon 2018). The current study addresses this concern and examines the effect of

50 using a simple shear capacity adjustment factor on the structural reliability of prestressed concrete

51 (PC) bridge girders. The purpose of the adjustment factor is to enhance the accuracy of shear

52 assessment with minimal additional effort, potentially enabling bridge girders to meet target

53 reliability levels in the rating process.

54 Since 2003, with the publication of the Manual for Condition Evaluation and Load and

55 Resistance Factor Rating (LRFR) of Highway Bridges, rating bridge girders for vehicular traffic

56 has been implicitly based on an assessment of structural reliability. The Manual for Bridge

57 Evaluation (MBE) was later published by AASHTO in 2008 (AASHTO 2008), replacing the initial

58 LRFR specifications as well as the alternative 1998 Manual for Condition Evaluation of Bridges

59 (based on Load Factor Rating, which was not reliability-based). The live load factors specified in

60 the MBE were later revised in 2011 (Sivakumar and Ghosn 2011) using weigh-in-motion (WIM)

61 data from truck traffic collected from six states. Based on a 5-year return period for load rating,

62 the recalibrated MBE rating process was formulated to result in an average target reliability index

63 of 2.5, with a minimum level of 1.5 for any particular structure. For bridge girders rated according

64 to the MBE, shear capacity is assumed to be calculated based on procedures specified in AASHTO

65 LRFD, although more refined procedures are allowed (AASTHO 2017).

Prior to the release of the $1^{\text {st }}$ Edition of AASHTO LRFD in 1994 (AASHTO 1994), bridge

67 girders in the United States were primarily designed to at least meet the minimum standards given

68 by the AASHTO Standard Specifications for Highway Bridges, which was last published in 2002

69 (AASHTO 2002). The shear design provisions in the AASHTO Standard Specifications were very

70 similar to those currently presented by the American Concrete Institute Building Code 
71 Requirements for Structural Concrete (ACI 318, 2014), where the concrete contribution to shear

72 strength is taken as an empirical function of the square root of concrete compressive strength.

73 However, a major change in shear design provisions was presented in AASHTO LRFD, where

74 shear capacity is based on the Modified Compression Field Theory (MCFT) (Vecchio and Collins,

75 1986), resulting in a significantly more complex, and often more accurate method than that used

76 in the Standard Specifications. The theoretically-developed MCFT provided significant changes

77 in calculation of the concrete shear strength contribution, diagonal crack angle, and maximum

78 allowable shear stress.

79 Since the 1994 AASHTO LRFD code was released, revisions to the shear design procedure

80 were published in subsequent editions of the specifications. These revisions were primarily made

81 to simplify the procedure, although the resulting nominal shear capacity was not substantially

82 changed. During this time, additional research has been conducted on the shear behavior of PC

83 beams. In some research, good agreement was found between the code model and experimental

84 results. However, as noted above, in other cases, significant discrepancies have been demonstrated

85 (Hawkins and Kuchma, 2007; Hawkins et al. 2005; Laskar et al. 2010; Pei et al. 2008; Chehab et

86 al. 2018). These discrepancies motivated the development of the shear capacity adjustment factor

87 suggested by Chehab and Eamon (2018) which is considered in this study.

88 AASHTO LRFD Shear Design Procedure

89

90 Two procedures are given in AASHTO LRFD (AASHTO 2017) to determine nominal shear

91 resistance; the General Procedure and the Simplified Procedure. The MCFT-based General

92 Procedure, generally thought to be most accurate, is the concern of this study. In this method, the

93 nominal shear resistance, $V_{n}$, of PC girders is taken as the lesser of Equations (1) or (2): 
$94 \quad V_{n}=V_{c}+V_{s}+V_{p}=0.083 \beta \sqrt{f_{c}^{\prime}} b_{v} d_{v}+\frac{A_{v} f_{y} d_{v}(\cot \theta)}{s}+V_{p}$

$95 \quad V_{n}=0.25 f_{c}^{\prime} b_{v} d_{v}+V_{p}$

96 where $V_{c}$ is the shear capacity attributed to the concrete; $V_{s}$ is the shear capacity attributed to the

97 web reinforcement; $V_{p}$ is the vertical component of the prestressing force; $\beta$ is a factor indicating

98 the ability of diagonally cracked concrete to transmit tension and shear; $f_{c}^{\prime}$ is the compressive

99 strength of concrete; $b_{v}$ is the web width; $d_{v}$ is the effective shear depth, taken as the distance

100 between the resultants of the tensile and compressive forces due to flexure; $A_{v}$ is the area of the

101 transverse reinforcement (stirrups) at a spacing $s ; f_{y}$ is the yield stress of the transverse steel; and

$102 \theta$ is the principle compression angle. Note that Eq. 2 represents the upper limit of $V_{n}$, which is

103 intended to prevent a web crushing failure prior to yielding of the transverse reinforcement.

104 Typically, this limit does not govern the design shear capacity (Eamon et al., 2014).

105 For sections that contain at least the minimum specified amount of transverse reinforcement

$106 \quad\left(A_{v-\min }=0.083 \sqrt{f_{c}^{\prime}} \frac{b_{v} s}{f_{y}}\right), \beta$ is taken as:

$107 \quad \beta=\frac{4.8}{\left(1+750 \varepsilon_{s}\right)}$

108 where $\varepsilon_{s}$ is the net longitudinal tensile strain in the section at the centroid of the tension

109 reinforcement, given by:

$110 \quad \varepsilon_{s}=\frac{d_{v}}{\left(E_{s} A_{s}+E_{p} A_{p s}\right)}$ 
111 In this expression, $M_{u}$ is the factored moment; $N_{u}$ is the factored axial force; $V_{u}$ is the

112 factored shear load; $f_{p o}$ is a parameter usually taken as $0.7 f_{p u} ; E_{s}$ and $A_{s}$ are the Young's

113 Modulus and area of the nonprestressed steel on the flexural tension side; and $E_{p}$ and $A_{p s}$ are the

114 Young's Modulus and area of the prestressed steel on the flexural tension side, respectively. When

115 the calculated $\varepsilon_{s}$ is negative, it may be recomputed by replacing the dominator of Eq. 4 by

$116\left(E_{s} A_{s}+E_{p} A_{p s}+E_{c} A_{c}\right)$, where $E_{c}$ and $A_{c}$ are the elasticity modulus and cross sectional girder

117 area of concrete on the flexural tension side, respectively.

118 For sections that do not contain the minimum amount of shear reinforcement, $\beta$ becomes:

$119 \beta=\frac{4.8}{\left(1+750 \varepsilon_{s}\right)} \frac{51}{\left(39+s_{e x}\right)}$

120 The crack spacing parameter $s_{x e}$ is calculated as:

$121 s_{x e}=s_{x} \frac{1.38}{a_{g}+0.63}$

122 where $s_{x}$ is the lesser of $d_{v}$ or the maximum distance between layers of longitudinal crack control

123 reinforcement, and $a_{g}$ is the maximum aggregate size.

124 The value of $\theta$, regardless of the amount of transverse reinforcement, is given by:

$125 \theta=29+3500 \varepsilon_{s}$

\section{Shear Adjustment Factor}

127 The shear adjustment factor considered in this study is given by Chehab and Eamon (2018), and 128 is taken as:

129

$$
r_{\text {LRFD }}=0.0061 f_{c}^{\prime}+0.028 \sigma+0.0012 s\left(\frac{142}{A_{v}}\right)+0.00036 h-0.15
$$


130 where $f_{c}^{\prime}=$ concrete compressive strength (MPa); $\sigma=$ average stress in the section due to prestress

131 force $(\mathrm{MPa}) ; s=$ stirrup spacing $(\mathrm{mm})$; and $h=$ girder height $(\mathrm{mm})$. Using this procedure, shear

132 capacity is evaluated by multiplying the nominal shear capacity found from the LRFD General

133 Procedure (i.e. the result of Eq. 1) by the result of Eq. 8, where $r_{L R F D}$ is not to exceed the range:

$1340.88 \leq r_{L R F D} \leq 2.62$. To further enhance accuracy, Chehab et al. (2018) recommended to modify

135 the computation of $V_{n}$ in Eq. 1 by iterating until $V_{n}$ equals $V_{u}$ (from Eq. 4), by changing the value

136 of $V_{u}$ until balance occurs. As discussed in Chehab and Eamon (2018), Eq. 8 was developed from

137 a selection of experimental results and a database of validated finite element analyses. Its

138 applicability was to be limited to Type II, III, and IV AASHTO PC girders with $f_{c}^{\prime}$ from 38-55

$139 \mathrm{MPa}, \sigma$ from 3.4-17 $\mathrm{MPa}$, and $s$ from 75-610 mm, which represents the range of parameters for

140 which it was developed. Practically, Eq. 8 represents an estimation of the ratio of the "exact" shear

141 capacity to the nominal capacity found from the LRFD method.

142 Use of the above procedure was found to significantly improve accuracy as well as decrease

143 variability, while producing no unconservative estimations of shear capacity. A selection of the

144 results reported by Chehab and Eamon (2018) is shown in Fig. 1, where the ratio of an "exact"

145 assessment of shear capacity to the LRFD assessment of nominal shear capacity "Exact/LRFD" as

146 well as the ratio of exact shear capacity to that assessed by the use of Eq. 8 "Exact/(LRFD x $r_{L R F D}$

147 )" is shown for approximately 200 typical PC bridge girders. Here, the "exact" assessment is taken 148 as the shear capacity determined from an experimentally-validated finite element model (Chehab

149 et al., 2017; Chehab and Eamon 2018; Chehab et al., 2018). As shown in Fig. 1, the majority of

150 the unmodified LRFD results are substantially inconsistent, where the Exact/LRFD ratio ranged

151 from 0.88 to 2.62 , with an overall mean ratio of 1.67 and coefficient of variation (V) of 0.25 .

152 Particularly troublesome are the several cases with Exact/LRFD ratios below 1.0, indicating 
153 unconservative estimates of shear capacity. Use of Eq. 8 still results in substantial conservatism

154 overall, where the mean ratio of Exact/(LRFD x $\left.r_{L R F D}\right)$ is 1.38 . However, the upper range of ratios

155 is substantially decreased from 2.62 to 1.72 , with no cases where capacity is over-predicted.

156 Correspondingly, the consistency in shear capacity estimation is likewise greatly improved, with

$157 \mathrm{~V}$ reduced by approximately $50 \%$, to 0.12 . Note that the use of a refined finite element analysis

158 procedure (i.e. the "exact" approach) to evaluate shear capacity would reduce discrepancies even

159 further to near zero, but such an approach is not practical for routine bridge rating due to the 160 modeling skill and computational effort involved.

161 The normalized sensitivity of Eq. 8 to its input parameters is shown in Fig. 2. As indicated in 162 the figure, average prestress force has most influence on results, followed by transverse steel 163 spacing, whereas concrete strength and especially girder height have least influence. Due to the 164 general conservatism of the LRFD method, as shown in the Figure, all parameters positively 165 influence Eq. 8, and hence increase the (Exact/LRFD) $V_{n}$ ratio. As noted above, in some cases, 166 the LRFD approach was found to be unconservative, and in such cases it is possible for Eq. 8 to 167 produce a value less than 1.0 (due to the presence of the negative constant 0.15 in the expression). 168 Note that these results indicate the sensitivity of the $V_{n}$ ratio (Exact/LRFD) to these parameters, 169 not the direct sensitivity of $V_{n}$.

\section{Bridge Girders Considered for Rating Evaluation}

171 To examine the effect of using a more accurate shear capacity assessment method in rating such 172 as that given by Eq. 8, consideration should be given to location, where legal loads as well as rating 173 procedures vary from state to state. In this study, the State of Michigan is considered as an example, 174 which has relatively high legal loads (Eamon et al., 2016), and where use of the (generally) 175 significantly conservative existing procedure to evaluate shear capacity may be particularly 
176 detrimental. Once the location of consideration was selected, 20 hypothetical prestressed concrete

177 AASHTO bridge girders (including Types II, III and IV) of four span lengths (15.2, 24.4, 30.5 and

$17861 \mathrm{~m})$, and five girder spacings $(1.2,1.8,2.4,3.1$ and $3.7 \mathrm{~m})$, were considered for rating in

179 accordance to the current procedure specified in the MBE (AASHTO 2018).

180 According to the MBE, the rating factor for legal loads is determined by:

$181 \quad R F=\frac{\phi R_{n}-1.25 D C-1.5 D W}{\gamma_{L L}(L L+I M)}$

182 In the expression above, $R_{n}$ is the nominal resistance of the component; $D W$ and $D C$ are the dead 183 loads of the wearing surface and the remaining structural components, respectively; $I M$ is the 184 vehicular dynamic load allowance, specified as $33 \%$ of the vehicular static live load; and the 185 resistance factor $(\phi)$ is given as 0.9 for a shear limit state for PC beams.

186 The remaining parameters, $L L$ and $\gamma_{L L}$, represent the maximum shear load effect generated 187 from a legal vehicle configuration and the associated live load factor used for rating, respectively. 188 Here, the total legal vehicle shear load on the bridge is proportioned to an individual girder by a 189 distribution factor, as a function of bridge geometry, as specified in AASHTO LRFD (AASHTO 190 2017). For calculation of dead loads as well as the live load distribution factor, it is assumed that 191 bridges have a width of $14.6 \mathrm{~m}$ (two traffic lanes with shoulders) with a $230 \mathrm{~mm}$ thick concrete $192 \operatorname{deck}\left(f_{c s}^{\prime}=28 \mathrm{MPa}\right)$, and $65 \mathrm{~mm}$ wearing surface. A summary of design parameters used, which 193 are typical for many existing AASHTO-type PC bridge girders designed in Michigan as well as 194 other states, is given in the last column of Table 1. Note that many of these values vary, depending 195 on the specific bridge geometry considered.

196 The Michigan Department of Transportation (MDOT) procedure for load rating is more 197 complex than that of many other states, where 28 different legal truck configurations are 198 considered, each with different load factors. For the bridge spans considered in this study, two of 
199 these configurations govern, depending on span, and are shown in Fig. 3. Generally, rating factors

200 resulting from Eq. 9 that are greater than 1.0 are acceptable while those less than 1.0 require traffic

201 restriction across the structure.

202 Limit State Function

203 The limit state function considered for shear capacity evaluation can be simply written as:

$204 \quad g=R\left(R_{i}\right)-Q\left(Q_{i}\right)$

205 where $R$ is girder shear resistance, as a function of resistance random variables $R$, and $Q$ is the 206 maximum shear load that the girder experiences, as the sum of the dead and live load shear effects, 207 as a function of load random variables $Q_{i}$. These models and the corresponding random variables 208 are described below.

\section{Initial Resistance Model}

211 To provide an accurate assessment of the reliability level inherent in a given standard, it is

212 important that the reliability of a component is evaluated for the minimum requirements set by that

213 standard. In the general LRFD approach, this condition is expressed as: $\phi R_{n}=\sum \gamma_{i} Q_{i}$, (where $\gamma_{i}$

214 are load factors and $Q_{i}$ are load effects) which is the code-specified limit between acceptability

215 and non-acceptability. In the case of rating, acceptability is expressed in terms of the rating factor,

216 for which the limit is taken as 1.0. Setting Eq. 9 equal to 1.0 and solving for the required $R_{n}$ results 217 in:

$218 R_{n}=(1 / \phi)\left(1.25 D C+1.5 D W+\gamma_{L L}(L L+I M)\right)$

219 which, in this study, becomes the nominal shear resistance for consideration in reliability rating.

220 Here it should be noted that $R_{n}$ from Eq. 11 represents a notional, or theoretical resistance, used

221 for evaluation of the reliability level associated with the rating process, and does not necessarily

222 represent the resistance of an actual girder. This is analogous to the evaluation of components 
223 with resistance set just equal to the design limit for reliability assessment of design code

224 specifications, whereas overdesign of an actual girder, particularly for shear, is rarely unavoidable.

225 Statistical parameters of shear resistance uncertainties for typical PC bridge girders are

226 available, and have been conveniently expressed as a single random variable, $R$ (Nowak, 1999).

227 However, the development of these statistics have assumed that the existing code procedure is

228 sufficiently accurate to model capacity. In this study, however, it is suggested that simplified code

229 methods are not necessarily adequate for accurate assessment of rating reliability, and hence the

230 use of Eq. 8. This requires that the statistical parameters of girder shear resistance are recalculated.

231 Since Eq. 8 is a function of girder properties, the uncertainties associated with specific girder

232 designs must be established in order for Eq. 8 to be evaluated. To facilitate this, the set of girders

233 described above, corresponding to 20 hypothetical bridges with spans from 15.2-61 m and girder

234 spacing 1.2-3.7 m, are designed according to MDOT standards. These standards are identical to

235 AASHTO LRFD specifications, with the exception of a higher live load than the HL-93 design

236 load specified in the AASHTO code. For shear design, this is equivalent to satisfying Eq. 11, but

237 in this case, $L L$ is determined not from legal loads but from the MDOT-specified HL-93-mod

238 design load (taken from 1.2 - 2.7 times higher than AASHTO's HL-93 load, depending on the

239 spans considered here), and the live load factor $\left(\gamma_{L L}\right)$ is specified as 1.75 .

240 Resistance random variables used for reliability analysis are given in Table 1, where statistical

241 parameters, in terms of coefficient of variation $(V)$ and bias factor $(\lambda$, the ratio of mean to nominal

242 value) are taken as those used to calibrate the AASHTO LRFD Specifications for consistency with

243 previously established reliability levels (Ellingwood et al. 1980, Siriaksorn 1980; Nowak 1999;

244 Nowak and Szerszen 2003; Yamani 1992). 
For comparison purposes, it is useful to first evaluate reliability based on resistance

246 established with the current, or initial LRFD model, without application of Eq. 8. In this initial

247 resistance model, Eq. 11 is first used to determine the required nominal shear capacity for a girder,

$248 R_{n}$, for a given bridge span and girder spacing. A hypothetical girder design is then developed to

249 exactly match this required value using the exiting LRFD shear procedure (Eqs. 1-7). Resistance

$250(R)$ in Eq. 10 thus becomes a function of Eqs. 1-7, above, with all equation parameters no longer

251 deterministic but replaced with the appropriate random variables shown in Table 1; either directly,

252 such as random variables $R_{1}, R_{2}, R_{4}, R_{5}$, etc., which have a corresponding parameter in Eqs. 1-7,

253 or replaced with functions of these random variables such as the parameter $d_{v}$, which can be

254 expressed as an algebraic function of random variables $\mathrm{R}_{3}\left(d_{e}\right), \mathrm{R}_{7}\left(f_{p u}\right), \mathrm{R}_{9}\left(A_{p s}\right), \mathrm{R}_{10}\left(b_{e}\right)$, and

$255 \mathrm{R}_{13}\left(f_{c s}^{\prime}\right)$ applicable for the design cases considered. Exceptions are parameters $E_{s}$ and $A_{s}$, which

256 appear in Eq. 4, parameters for longitudinal non-prestressed (mild) steel, which is not used in the

257 prestressed girder designs considered, and parameter $a_{g}$, in Eq. 6, which is taken as a deterministic

258 value.

\section{Updated Resistance Model}

The updated resistance model considers the effect of Eq. 8 in the shear resistance evaluation. This

263 model is identical to the initial model described above, except now the resistance function is

264 multiplied by the result of Eq. 8. Note that the girder design itself is unchanged, only the evaluation

265 of its capacity $R$ for reliability analysis within Eq. 11. When reliability is evaluated considering

266 Eq. 8, its result is no longer a deterministic value, but its input parameters $\left(f_{c}^{\prime}, \sigma, s, A_{v}\right.$, and $\left.h\right)$ also

267 become functions of the random variables given in Table 1 . Of these, $R_{1}, R_{4}, R_{6}$, and $R_{11}$ directly 
268 replace parameters $f_{c}^{\prime}, A_{v}, s$, and $h$, respectively, while $\sigma$ is expressed as a function of random

269 variables $\mathbf{R}_{2}\left(b_{v}\right), \mathbf{R}_{7}\left(f_{p u}\right), \mathbf{R}_{9}\left(A_{p s}\right)$, and $\mathbf{R}_{11}(h)$.

\section{Simplified Resistance Model}

This model is used only as part of the model verification process, as discussed further below. In

273 this case, rather than forming a resistance function with Eqs. 1-7 and using the fundamental random

274 variables given in Table 1, girder shear resistance is taken as a single random variable $R$, using the 275 final shear resistance parameters reported for the LRFD calibration (where $R$ is lognormal with $\lambda_{R}$ $276=1.15$ and $\left.V_{R}=0.14\right)$. This model represents the approach used in the LRFD and MBE calibrations

277 to compute reliability indices. As with the other resistance models above, the nominal value for $R$ 278 is determined from Eq. 11.

279 Professional Factor

For this study, one resistance random variable that requires further consideration is the professional

282 factor $(P)$, which is used to account for uncertainty in the analysis model used to establish member 283 strength. In the initial AASHTO LRFD calibration, $P_{\text {LRFD }}$ was taken to have a bias factor of $284 \lambda=1.075$ with $V=0.10$ (Nowak 1999). $P_{\text {LRFD }}$ is used in this study when the Initial Resistance Model 285 is considered. Although the origin of these values are not clearly documented, these statistics 286 appear to greatly underestimate the actual level of uncertainty and conservatism in the LRFD shear 287 capacity model. For example, if the results of Chehab and Eamon (2018) are considered, the 288 resulting statistics for $P$ for the LRFD model are $\lambda=1.67$ and $V=0.25$, whereas the adjustment of 289 Eq. 8 produces an estimated $P$ factor of $\lambda=1.38$ and $V=0.12$. As expected, Eq. 8 results in less 290 conservatism as well as less variation than the unmodified LRFD procedure.

291 In general, for reliability analysis using Eq. 8, when the Updated Resistance Model is 292 considered, it is desirable to use the most accurate statistics for $P$ that are available. However, 
293 because the target reliability levels within the MBE were set with what appears to be non294 representative $P$ factor statistics, using the correct bias factor for Eq. 8 would produce nonsensical 295 results in the context of the MBE. This difficulty can be illustrated as follows. As discussed above, 296 Eq. 8 has shown to produce both lower conservatism as well as lower variation from the existing 297 model; i.e. $\lambda$ as well as $V$ have decreased, as would be expected from any model improvement. 298 However, the values of $\lambda=1.075, V=0.10$ were used for the existing model in the LRFD and MBE 299 calibrations to set the target reliability indices rather than the reportedly more accurate values of $300 \lambda \lambda=1.67$ and $V=0.25$. Because of this, if the correct $P$ factor associated with Eq. 8 is used for 301 reliability assessment, an improvement in model accuracy would not be indicated, but rather 302 accuracy will have nominally worsened, as both $P$ factor values $\lambda$ and $V$ associated with Eq. 8 (1.38 303 and 0.12 , respectively) are greater than the values used for the existing model used in the MBE 304 calibration (1.075 and 0.10 , respectively).

305 Ideally, the MBE shear results would be recalculated, and new shear reliability targets set with 306 the existing LRFD model while using the more accurate $P$ factor values of $1.67,0.25$. This would 307 allow direct use of the correct $P$ factor values associated with the updated shear model in reference 308 to the existing MBE reliability targets. However, recalibration of the MBE is not a practical 309 solution, at least in the context of this study. As an alternative, rather than recalibrating the MBE, 310 the $P$ factor for Eq. 8 can be calibrated to fit within the context of the MBE. The calibrated $P$ 311 factor should represent an equivalent degree of model improvement from the LRFD model, but 312 yet remain compatible with original MBE assumptions.

313 Although alternate ways of calibrating the $P$ factor may by possible, the method suggested 314 here is to scale the correct $P$ factor to the assumed baseline of the MBE while maintaining the 315 correct proportional differences in the models. The calibrated coefficient of variation for $P$ is then 
316 simply: $V_{E Q 8}=V_{L R F D} \cdot\left(V_{c E Q 8} / V_{c L R F D}\right)$, where $V_{L R F D}$ is the value originally used in the MBE for the

317 existing LRFD model (i.e. $V_{L R F D}=0.10$ ), and $V_{c E Q 8}, V_{c L R F D}$ are the 'correct' values for the updated

318 shear model and LRFD models, respectively $\left(V_{c E Q 8}=0.12\right.$ and $\left.V_{c L R F D}=0.25\right)$. Using this

319 expression produces a calibrated coefficient of variation $\left(V_{E Q 8}\right)$ of 0.048 .

320 A similar process can be used to calibrate bias factor, but the calibration scale must be adjusted

321 to a baseline of 1.0 (which indicates no bias) rather than 0 as used for $V$ (which indicates no

322 variation $)$, resulting in: $\lambda_{E Q 8}=1.0+\left(\lambda_{L R F D}-1.0\right) \cdot\left(\lambda_{c E Q 8} / \lambda_{c L R F D}\right)$. This expression produces a

323 calibrated bias factor of $\lambda_{E Q 8}=1.062$. Thus, the resulting scaled $P$ factor $\left(P_{E Q 8}\right)$ values of $\lambda=1.062$

324 and $V=0.048$ are used when Eq. 8 is considered to compute shear resistance; i.e. when the Updated

325 Resistance Model is considered.

326 It must be emphasized that an adjustment of this nature is essential, as if it was not done and

327 the uncalibrated $\lambda_{c E Q 8}$ and $\lambda_{c L R F D}$ bias factors were used, mean capacity and hence reliability index

328 of the Updated and Initial Models would be significantly over-predicted relative to the MBE

329 reference reliability levels. In the reliability analysis for both models, $P$ is introduced as an

330 additional random variable multiplied with the resistance function (i.e. as $P_{L R F D}$ for the Initial

331 Model and $P_{E Q 8}$ for the Updated Model). Note for the Simplified Resistance Model, the $P$ factor

332 given for the Initial Resistance Model $\left(P_{L R F D}\right)$ was already included in the final resistance statistics

333 reported in Table 1 for $R$ (Nowak 1999).

334

335

336

337

338

339

340

\section{Load Models}

The dead load model is composed of random variables describing variation in the weight of prefabricated components $\left(Q_{P}\right)$ such as the girders; site-cast components $\left(Q_{S}\right)$ such as the deck and barriers, and the wearing surface $\left(Q_{W}\right)$. Statistical parameters are taken as those used to calibrate the AASHTO MBE and LRFD (Nowak, 1999), and are given in Table 2. Dead load RVs 
341 are normally distributed. The live load model is taken from Eamon et al. (2016), and was developed

342 from 66 million truck records collected over two years of weigh-in-motion data representing legal

343 and permit vehicles across twenty sites on Michigan roadways. Actual vehicle load effects were

344 calculated by incrementing the recorded vehicle configurations and spatial relationships across a

345 beam model of the considered span length. It was found that the extreme (high) values of load

346 effect well-fit a normal distribution. Correspondingly, load effects were then statistically projected

347 with extreme value theory to determine maximum expected load statistics for a 5-year return

348 period, similar to the process used to set legal and routine permit reliability levels in the MBE.

349 Live load uncertainties include those from the data projection $\left(V_{\text {proj }}\right)$, geographic location $\left(V_{\text {site }}\right)$,

350 the data collection at a particular site $\left(V_{\text {data }}\right)$, and vehicle dynamic load $\left(V_{I M}\right)$. Values were taken

351 as 0.02 for $V_{\text {data }}$, and 0.09 and 0.055 for $V_{I M}$ for single lane and two-lane load effects, respectively

352 (Eamon et al. 2016). Values for the mean maximum shear effect, $V_{\text {proj }}$, $V_{\text {site }}$, and the final

353 resulting coefficient of variation of shear effect, $V_{L \max }$, are span-dependent and given in Table 3.

354 Live load effects are distributed to the girder using AASHTO LRFD distribution factors,

355 which were similarly used in the AASHTO LRFD and MBE reliability calibration efforts. For the

356 spans considered in this study, the one-lane shear live load effect governs for the Michigan-specific

357 data, as discussed below (Eamon et al. 2016). The corresponding live load distribution factor for

358 shear is taken as: $0.36+0.131 S$, where $S(\mathrm{~m})$ is girder spacing (AASHTO 2017). Note that an

359 additional source of uncertainty that may be considered is that due to vehicle live load distribution

360 to the girders, which generally results in a net increase in calculated girder reliability due to the

361 conservativeness of the AASHTO LRFD load distribution expressions. However, a concern with

362 this adjustment is that it is primarily due to the edge the stiffening effect of barriers (Eamon and 
363 Nowak 2002; 2005), which, although are effective in reducing girder live load under service loads,

364 are not designed nor intended to act as primary structural elements and may not be reliable in

365 aiding load distribution during an overload. Therefore, this adjustment may not be desirable in

366 rating and was not included in this study. Rather, load distribution was conservatively taken as

367 deterministic, as it was for the AASHTO LRFD calibration (Nowak 1999).

\section{Verification of Reliability Model}

369 Prior to evaluating the effects of the Updated Resistance Model, the girder reliability indices 370 computed from this study using the Initial Resistance Model should be similar to those that were

371 found during the initial calibration of the AASHTO Specifications. A verification of the model

372 used here is necessary because the basic shear resistance random variables that were used to

373 calibrate the AASHTO specifications, as well as the exact version of the method used to evaluate

374 shear capacity, were not clearly documented (Nowak, 1999; Kulicki et al., 2007). It is important

375 that the Initial Resistance Model considered in this study produces similar results as that used to 376 develop the MBE, if the target reliability indices specified for the MBE are to have meaningful

377 comparison value to the results of the Updated Resistance Model. Here note that AASHTO LRFD

378 calibration information is referenced, in which girder shear resistance statistics were developed

379 and later used for the MBE calibration as well.

380 For the validation, using the load models considered in the AASHTO LRFD code calibration, 381 (the same dead load model discussed above, but the live load model is not Michigan-specific) 382 (Nowak 1999), reliability index was computed using the First Order Reliability Method (FORM) 383 (Rackwitz and Fiessler 1978) for a selection of typical PC girders, where girder shear resistance is 384 computed with the Initial Resistance Model. The results of this calculation are given in Fig. 4, and 385 are compared to the values reported for the AASHTO LRFD Calibration ("LRFD"). As shown in 
the figure, results are very similar, and nearly exact in most cases. As a second means of

387 verification, the Simplified Resistance Model was also considered. In this case, it was found that

388 reliability results were also very close to the LRFD calibration results, as shown in Fig. 4.

389 Therefore, the resistance model used in this study was taken as validated. Note that the target

390 reliability indices shown in Fig. 4, specified for design, are substantially higher (from 3.5 to 4)

391 than those which are specified for rating (from about 1.5 to 2.5; see Results discussion next).

\section{$392 \quad$ Results}

393

394

The reliability index for Eq. 10 is computed using FORM, and results are given in Figs. 5-7. In

395 the figures, reliability indices are given in order for 4 span lengths with 5 girder spacings each

396 (from 1.2 to $3.7 \mathrm{~m}$ ), for different methods of computing girder resistance. For various cases,

397 FORM results were verified with Monte Carlo Simulation using $1 \times 10^{6}$ simulations, and were

398 found to be nearly identical (differences in reliability index less than 1-2\%).

399 Fig. 5 presents results using the Simplified Resistance Model (i.e. that used in the MBE and

400 LRFD calibrations), where $R$ is taken as a single random variable with constant statistical

401 parameters $\left(\lambda_{R}=1.15\right.$ and $\left.V_{R}=0.14\right)$ for all girders. As shown, the values in Fig. 5 are substantially

402 lower than those given in Fig. 4, where the only difference between the results shown in Figs. 4

403 and 5 is the live load model used. This difference is expected, as the Michigan live load data have

404 larger load effects than those used for the LRFD code calibration (Eamon et al. 2016). Although

405 not as severe as those in Michigan, the load effects of some states considered in the MBE

406 calibration were found to have relatively high load effects as well, resulting in a target reliability

407 index for rating of 2.5, with a minimum index allowed for any girder of 1.5 (Sivakumar and Ghosn

408 2011) (compared to a target as well as minimum allowed reliability index for design with

409 AASTHO LRFD of 3.5). Also note that the values given in Fig. 5 have a larger variation than 
410 those given in Fig. 4. This is also due to the different live load model used. In the LRFD calibration

411 live load model, two-lane load effects always governed; thus, the distribution factor used to

412 distribute live load shear to a girder for design is the same factor as that used in the reliability

413 analysis (Nowak 1999). However, for the Michigan traffic data, it was found that multiple very

414 heavy vehicles in a single lane dominated the shear load effect (Eamon et al. 2016). In this case,

415 although a two-lane distribution factor still must be used for design for a two-lane bridge (as well

416 as for rating, for legal and routine permit loads), a single lane distribution factor is used in the

417 reliability analysis to proportion the dominant single lane load effect to the girder. For the spans

418 considered, it can be shown that the ratio of the single lane to the two-lane distribution factor

419 increases as girder spacing decreases. Thus, the proportion of actual shear load (based on the 1-

420 lane factor) to the shear load used for rating (based on the two-lane factor) similarly increases

421 (Eamon et al. 2016). This causes a drop in reliability level for more closely-spaced girders. As

422 shown in the figure, reliability indices ranged from 1.37 to 2.36 , with a mean value of 1.87 . As the

423 target reliability index of MBE-rated girders is a minimum of 1.5 in any case and 2.5 overall, two

424 considered girders currently do not meet the individual minimum, and the group overall does not

425 meet the average required.

426 Fig. 6 results are computed based on the Initial Resistance Model, where resistance is

427 evaluated as a function of the basic random variables given in Table 1 and Eqs. 1-7, rather than

428 the single resistance random variable used in the original LRFD calibration (the Simplified

429 Model). The average reliability results of Figs. 5 and 6 are similar, as expected, since the resistance

430 models are the same as those used to compute the design reliability indices shown in Fig. 4, which

431 show very close results for these two resistance models when the nominal girder resistances used

432 for the LRFD calibration are considered. However, although the average reliability shown in Fig. 
4336 for the Initial Model (1.93) is very close to that using the Simplified Model shown in Fig. 5

434 (1.87), there is substantially more variation of reliability shown in Fig. 6, where reliability indices

435 range from 1.1 to 2.69 . This is because the constant, single variable $(R)$, resistance statistics used

436 for all girders in the MBE and LRFD calibrations as per the Simplified Model, which represents a

437 typical value, actually varies somewhat depending on the specific girder geometry considered.

438 This variation becomes apparent when a different set of girders (i.e. those appropriate for MI traffic

439 loads) are considered rather than the set corresponding to the hypothetical girder resistance values

440 used in the LRFD calibration.

441 Here again, the average reliability index of 1.93 is shown to be below that required (2.5), and

4424 girders have reliability below the minimum of 1.5 required. This represents a significant

443 problem, as these reliability indices are based on non-deteriorated resistance (see Eq. 11); i.e. some

444 existing structures, as-designed, will not meet rating reliability requirements. This finding would

445 require recalibration of Michigan's live load model used for rating, resulting in an increase of the

446 required live load factors used for rating and a decrease in the rating factor for bridges with PC

447 girders. Practically, this may result in additional traffic restrictions on numerous structures.

$448 \quad$ Fig. 7 provides girder reliability indices when the adjustment suggested by Eq. 8 is used to 449 evaluate shear capacity and thus the Updated Model is evaluated. To illustrate the effect of Eq 8. 450 on results, three different girder designs were developed for each bridge case. The middle line 451 represents typical girder designs used in Michigan, those commonly considered for the span and 452 girder spacing considered. The upper and lower lines represent designs using different concrete 453 strengths and corresponding stirrup spacings, but such that the nominal shear capacity is 454 unchanged $\left(f^{\prime}{ }_{c}\right.$ and stirrup spacing vary, but are within the range shown in Table 1 , across the spans 455 and girder spacings considered, where higher $f^{\prime}{ }_{c}$ and wider stirrup spacing $(s)$ result in the higher 
456 reliability cases when Eq. 8 is applied; see Fig. 2). Comparing Fig. 6 and Fig. 7 results, it can be

457 seen that only minor differences occur for typical designs within the smallest span (15.2 m) when

458 Eq. 8 is applied, whereas much larger differences in reliability assessment occur for the longer

459 spans. This is because the existing LRFD procedure was found to be relatively accurate for the

460 lower prestress levels needed for the shorter spans; as the spans increase, the section prestress level

461 increases, causing a greater discrepancy between the capacity provided by the LRFD method and

462 the adjustment from Eq. 8 (see Fig. 2). Using Eq. 8 to evaluate capacity results in reliability indices

463 for typical designs ranging from 1.81 to 4.81 , with an average of 3.77 . Thus, in the case of

464 Michigan bridge girders, this more accurate shear assessment allows all typical girder designs to

465 meet minimum required reliability targets, avoiding unnecessary traffic restrictions as well as over-

466 rating shear resistance in some cases.

467 Note that the reliability targets in the MBE were set considering girders in an undeteriorated 468 state, as are the reliability results shown in Figs. 5-7. However, clearly, as girders deteriorate, 469 shear capacity, and hence reliability, may drop. If the reliability index of a girder drops below the 470 minimum acceptable level, either the girder must be repaired, or traffic must be restricted to restore 471 reliability to that required target level. In the rating process, the rating factor is used as a surrogate 472 metric for assessment of adequate reliability. Note that Eq. 8 does not have specific input 473 parameters for material deterioration or other types of environmental damage. However, such 474 damage can be accounted for in the rating procedure using Eq. 8 in the same way that existing 475 code procedures can be used to do so. That is, $V_{n}$ using the adjustment of Eq. 8 can be calculated 476 with reduced $f_{c}^{\prime}$, web thickness, area of steel, prestress force, etc., as appropriate, based on semi477 annual inspection and evaluations of the structure, to account for concrete deterioration and steel 478 corrosion. Thus, whether undamaged or deteriorated girders are considered, a more accurate 
assessment of actual shear capacity and rating factor can be obtained, and hence a more accurate

480 assessment of shear reliability relative to the target levels. To show the practical effect of the use

481 of Eq. 8 in the reliability-based rating of existing structures, Fig. 8 provides the fractional reduction

482 in nominal shear capacity $\left(V_{n}\right)$ allowed that would provide a reliability index equal to 2.5 . In

483 particular, if $V_{n}$ is reduced to the fraction shown in Fig 8 due to, say, a loss of transverse steel area

484 from corrosion or concrete web area from spalling, a reliability index of 2.5 could still be

485 maintained. As shown in the figure, most cases allow $V_{n}$ to be reduced to about $80-90 \%$ (i.e. a loss

486 of 10-20\%) of its nominal value while still maintaining an acceptable level of reliability for rating.

\section{Summary and Conclusion}

488 In this study, the effect of using a simple procedure to enhance the accuracy of shear capacity 489 prediction on PC bridge girder reliability in the rating process was examined. Although more 490 accurate methods for shear capacity evaluation are available, such as a detailed finite element 491 approach, such methods are associated with substantial effort and knowledge to implement and 492 are generally impractical for routine bridge rating. Although conservative, a simple method such 493 as that considered in this study is easy to implement, and can provide moderate increases in 494 accuracy.

495 As a result of the study, it was found that significantly more variation in shear reliability in 496 PC girders exists than assumed in the LRFD and MBE calibrations even when using the existing 497 shear capacity and load models without adjustment. This was due to the use of a constant bias 498 factor for shear resistance development, where use of a more detailed reliability model revealed 499 that resistance statistical parameters vary with beam geometry. For girders on the edge of 500 acceptability, such modeling, such as that used in this study, may be useful to prevent bridge 501 posting. 
It was also found that using the simple shear adjustment factor considered may provide 503 significant advantages in bridge rating. Using Michigan PC bridge girders as an example, prior to 504 application of the shear adjustment factor, several cases were found to have reliability indices 505 below the minimum and average required rating reliability levels. Conversely, reliability indices were found to have met the required levels when the shear adjustment factor was applied, thus 507 avoiding potentially rating structures unconservatively as well as reducing unnecessary traffic 508 restrictions.

509 Because most code-based procedures are conservative, the use of many refined techniques, 510 whether for capacity analysis such as that presented here, or, for example, the use of finite element 511 analysis for load distribution in lieu of the AASHTO expressions, frequently result in more 512 accurate, but less-conservative results. Although the AASHTO specifications allow such refined 513 methods, the code reliability targets, whether for rating or design, were set based on less accurate, 514 but more conservative methods. Thus, applying refined methods, such as Eq. 8, will practically 515 result in a lower safety margin overall than if the less accurate methods are used, even if the 516 required code reliability indices are met. If the overall reduction in conservatism is of concern, a 517 possible solution that retains the accuracy of the refined method, as well as the prior level of 518 conservatism, is to introduce an additional resistance factor with the refined procedure. This factor 519 would be set such that the average level of reliability using the refined method matches that for 520 the same structures analyzed using the code-based methods. As such, an adjustment is not 521 required, however, most agencies may be reluctant to implement this approach, particularly in the 522 context of rating. Regardless, although this is a broad issue and is beyond the scope of this study 523 to fully address, it should be considered in the use of any refined technique such as that presented 524 in the present paper. 
537 References

538 AASHTO. (1994). LRFD bridge design specifications, $1^{\text {st }}$ Ed. American Association of State 539 Highway and Transportation Officials, Washington, D.C.

540 AASHTO. (2002). Standard specifications for highway bridges, 17th Ed. American Association of State Highway and Transportation Officials, Washington, D.C.

542 AASHTO. (2008). Manual for bridge evaluation, 1st Ed. American Association of State Highway and Transportation Officials, Washington, D.C.

544 AASHTO. (2017). LRFD bridge design specifications, 8th Ed. American Association of State 545 Highway and Transportation Officials, Washington, D.C.

546 AASHTO. (2018). Manual for bridge evaluation, 3rd Ed. American Association of State Highway and Transportation Officials, Washington, D.C. 
548 ACI (American Concrete Institute). (2014). "Building code requirements for structural concrete and commentary." ACI 318-14, Farmington Hills, MI.

550 Chehab, A. I., \& Eamon, C. D. (2018). "Regression-based adjustment factor to better estimate shear capacity for load-rating simple span PC girders." J. Bridge Eng., 10.1061/(ASCE)BE.1943-5592.0001224, 04018017.

Chehab, A. I., Eamon, C. D., Parra-Montesinos, G. J., \& Dam, T. X. (2018). "Shear testing and modeling of AASHTO type II prestressed concrete bridge girders." ACI Struct. J, 15(3), 801-8011.

Chehab, A., Dam, T., Eamon, C. D., and Parra-Montesinos, G. (2017). "Finite element modeling of shear failure in prestressed concrete AASHTO beams." Proc., PCI Convention and National Bridge Conf., Precast/Prestressed Concrete Institute, Chicago.

Eamon, C. D., Parra-Montesinos, G., and Chehab, A. (2014). "Evaluation of prestressed concrete beams in shear." MDOT Rep. RC-1615, Michigan DOT, Lansing, MI.

Eamon, C., Kamjoo, V., and Shinki, K. (2016). "Design live-load factor calibration for Michigan highway bridges.” J. Bridge Eng., 10.1061/(ASCE)BE.1943-5592.0000897, 04016014.

Eamon, C., and Nowak, A. S. (2002). "Effects of Edge-Stiffening Elements and Diaphragms on Bridge Resistance and Load Distribution,” J. Bridge Eng., Vol. 7, No. 5, pp. 258-266.

Eamon, C. and Nowak, A.S. (2005). "Effect of Edge-Stiffening and Diaphragms on the Reliability of Bridge Girders," J. Bridge Eng., Vol. 10, No. 2, pp 206-214.

Ellingwood, B., Galambos, T.V., MacGregor, J.G. and Cornell, C.A., "Development of a Probability Based Load Criterion for American National Standard A58”, NBS Special Report 577, U.S. Department of Commerce, National Bureau of Standards, 1980. 
Hawkins, N. M., and Kuchma, D. A. (2007). “Application of LRFD bridge design specifications to high-strength structural concrete: Shear provisions.” NCHRP Rep. 579, Transportation Research Board, Washington, DC.

Hawkins, N. M., Kuchma, D. A., Mast, R. F., Marsh, M. L., and Reineck, K.-H. (2005). "Simplified shear design of structural concrete." NCHRP Rep. 549, Transportation Research Board, Washington, DC.

Kulicki, J. M., Prucz, Z., Clancy, C. M., Mertz, D. R., \& Nowak, A. S. (2007). "Updating the calibration report for AASHTO LRFD code." NCHRP Rep. 20-7(186), Transportation Research Board, Washington, D.C.

Laskar, A., Hsu, T. C., and Mo, Y. L. (2010). "Shear strengths of prestressed concrete beams, Part 1: Experiments and shear design equations.” ACI Struct. J., 107(3), 330-339.

Llanos, G., Ross, B. E., and Hamilton, H. R. (2009). "Shear performance of existing prestressed concrete bridge girders." BD545-56, Dept. of Civil and Coastal Engineering, Univ. of Florida, Gainesville, FL, 160.

MDOT (Michigan DOT). (2009). Bridge analysis guide: 2005 ed., with 2009 interim update, parts 1 and 2. MDOT Construction and Technology Support Area, Lansing, MI.

Nowak, A.S. (1999). "Calibration of LRFD bridge design code.” NCHRP Rep. 368. Transportation Research Board, Washington, D.C.

Nowak, A.S. and Szerszen, M.M., 2003, "Calibration of Design Code for Buildings (ACI 318): Part 1-Statistical Models for Resistance.” ACI Structural Journal, V. 100, No. 3, pp. 377382.

Pei, J. S., Martin, R. D., Sandburg, C. J., and Kang, T. H. (2008). "Rating precast prestressed concrete bridges for shear." FHWA-OK-08-08, Univ. of Oklahoma, Norman, OK. 
593 Rackwitz, R., and Fiessler, B. (1978). "Structural reliability under combined random load 594 sequences.” Computers \& Structures, 9(5), 489-494.

595 Ross, B. E., Ansley, M., and Hamilton, H. R. (2011). "Load testing of 30-year old AASHTO Type 596 III highway bridge girders.” PCI J., 56(4), 152-163.

597 Siriaksorn, A., (1980), "Serviceability and Reliability Analysis of Partially Prestressed Concrete 598 Beams", Ph. D. Thesis, The University of Illinois at Chicago Circle.

599 Sivakumar, B., \& Ghosn, M. (2011). "Recalibration of LRFR live load factors in the AASHTO 600 manual for bridge evaluation." NCHRP Project, 20-07. Transportation Research Board, $601 \quad$ Washington, DC.

602 Vecchio, F. J., and Collins, M. P. (1986). "The modified compression-field theory for reinforced 603 concrete elements subjected to shear.” ACI J., 832(2), 219-231.

604 Wilder, K., Lava, P., Debruyne, D., Wang, Y., De Roeck, G., and Vandewalle, L. (2015). “Stress 605 field based truss model for shear-critical prestressed concrete girders." Structures, 3(Aug), 606 $28-42$.

607 Yamani, A. S. (1992). "Reliability evaluation of shear strength in highway girder bridges (Doctoral 608 dissertation)." Univ. of Michigan, Ann Arbor, MI.

609

610

611

612

613

614

615

616

617

618

619

620

621

622 
645 List of Tables

646 Table 1. Resistance Random Variables

Table 2. Dead Load Random Variables 
Table 1. Resistance Random Variables

\begin{tabular}{|c|c|c|c|c|c|c|}
\hline RV & & Parameter Name & $\begin{array}{l}\text { Bias } \\
\text { Factor }\end{array}$ & V & Distribution* & $\begin{array}{l}\text { Nominal } \\
\text { Value** }\end{array}$ \\
\hline $\mathrm{R}_{1}^{\mathrm{a}}$ & $f_{c}^{\prime}(\mathrm{MPa})$ & Concrete Strength & 0.95 & 0.150 & $\mathrm{LN}$ & $28-62$ \\
\hline $\mathrm{R}_{2}^{\mathrm{a}}$ & $b_{v}(\mathrm{~mm})$ & Web Width & 1.00 & $0.05-0.067$ & $\mathrm{~N}$ & $150-200$ \\
\hline $\mathrm{R}_{3}^{\mathrm{b}}$ & $d_{e}(\mathrm{~mm})$ & Strand Effective Depth & 1.00 & 0.017 & $\mathrm{~N}$ & $1065-1500$ \\
\hline $\mathrm{R}_{4}^{\mathrm{b}}$ & $A_{v}\left(\mathrm{~mm}^{2}\right)$ & Stirrup Area & 1.00 & 0.015 & $\mathrm{~N}$ & $140-250$ \\
\hline $\mathrm{R}_{5}^{\mathrm{b}}$ & $f_{y}(\mathrm{MPa})$ & Stirrup Yield Strength & 1.12 & 0.10 & $\mathrm{LN}$ & 414 \\
\hline $\mathrm{R}_{6}{ }^{\mathrm{c}}$ & $S(\mathrm{~mm})$ & Stirrup Spacing & 1.00 & 0.040 & $\mathrm{~N}$ & $75-610$ \\
\hline $\mathrm{R}_{7^{\mathrm{a}}}$ & $f_{p u}(\mathrm{MPa})$ & Strand Ultimate Strength & 1.04 & 0.025 & $\mathrm{LN}$ & 1,861 \\
\hline $\mathrm{R}_{8}^{\mathrm{a}}$ & $E_{p s}(\mathrm{MPa})$ & Strand Young's Modulus & 1.00 & 0.060 & $\mathrm{LN}$ & 196,500 \\
\hline $\mathrm{R}_{9}^{\mathrm{b}}$ & $A_{p s}\left(\mathrm{~mm}^{2}\right)$ & Strand Area & 1.00 & 0.0125 & $\mathrm{LN}$ & $1,615-$ \\
\hline $\mathrm{R}_{10}{ }^{\mathrm{a}}$ & $b_{e}(\mathrm{~mm})$ & Effective Width & 1.00 & $0.003-0.008$ & $\mathrm{~N}$ & $1,220-$ \\
\hline $\mathrm{R}_{11}^{\mathrm{b}}$ & $h(\mathrm{~mm})$ & Girder Height & 1.00 & 0.011 & $\mathrm{~N}$ & $915-1,370$ \\
\hline
\end{tabular}




\begin{tabular}{ccccccc}
$\mathrm{R}_{12}{ }^{\mathrm{b}}$ & $t_{s}(\mathrm{~mm})$ & Slab Thickness & 1.01 & 0.044 & $\mathrm{~N}$ & 230 \\
$\mathrm{R}_{13}{ }^{\mathrm{a}}$ & $f_{c s}^{\prime}(\mathrm{MPa})$ & Slab Concrete Strength & 0.99 & 0.15 & $\mathrm{LN}$ & 28 \\
& $P_{L R F D}{ }^{\mathrm{d}}$ & LRFD Professional Factor & 1.075 & 0.10 & $\mathrm{~N}$ & 1.0 \\
& $P_{E Q 8}$ & Eq. 8 Professional Factor & 1.062 & 0.048 & $\mathrm{~N}$ & 1.0 \\
\hline
\end{tabular}

*N=normal; $\mathrm{LN}=\log$-normal.

**Value depends on the specific girder design considered.

${ }^{\text {a} E l l i n g w o o d ~ e t ~ a l . ~ 1980 ; ~ b S i r i a k s o r n ~ 1980 ; ~ ' N o w a k ~ 1999 ; ~}{ }^{\mathrm{c}, \mathrm{d}}$ Nowak and Szerszen 2003

691

692

693

694

695

696

697

698

699

700

701

702

703

704

Table 2. Dead Load Random Variables

\begin{tabular}{ccc}
\hline $\mathrm{RV}$ & Bias Factor & $\mathrm{V}$ \\
\hline$Q_{P}$ & 1.03 & 0.08 \\
$Q_{S}$ & 1.05 & 0.10 \\
$Q_{W}$ & $*$ & 0.25 \\
*Wearing surface is taken as a mean thickness of $89 \mathrm{~mm}$.
\end{tabular}

705

706

707

708

709

710

711

712

713

714

715

716

717

718

719

720

721

722 
Table 3. Shear Live Load Statistics for Michigan-Specific Traffic

\begin{tabular}{ccccc}
\hline \multirow{2}{*}{ Span $(\mathrm{m})$} & Mean Maximum & \multicolumn{3}{c}{ Coefficient of Variation } \\
\cline { 2 - 4 } & Shear Load $(\mathrm{kN})$ & $V_{\text {proj }}$ & $V_{\text {site }}$ & $V_{\text {Lmax }}$ \\
\hline 15.2 & 712 & 0.035 & 0.12 & 0.14 \\
24.4 & 938 & 0.035 & 0.13 & 0.15 \\
30.5 & 1040 & 0.035 & 0.13 & 0.16 \\
61 & 1380 & 0.037 & 0.13 & 0.16 \\
\hline
\end{tabular}

746

747

748

749

750

751

752

753

754

755

756

757

758

759

760 


\section{List of Figures}

Fig. 1. Comparison of shear capacity ratios

Fig. 2. Normalized sensitivity results of shear resistance variables

Fig. 3. MDOT governing legal trucks considered for reliability analysis (data from MDOT 2009)

\section{$790 \quad$ Model}

Fig. 4. Reliability indices for typical PC girders using AASHTO LRFD load models

Fig. 6. Reliability indices for shear based on Michigan traffic loads and Initial Resistance Model

794 Model

795 Fig. 8. Acceptable reduction in $V_{n}$ for a reliability index of 2.5 


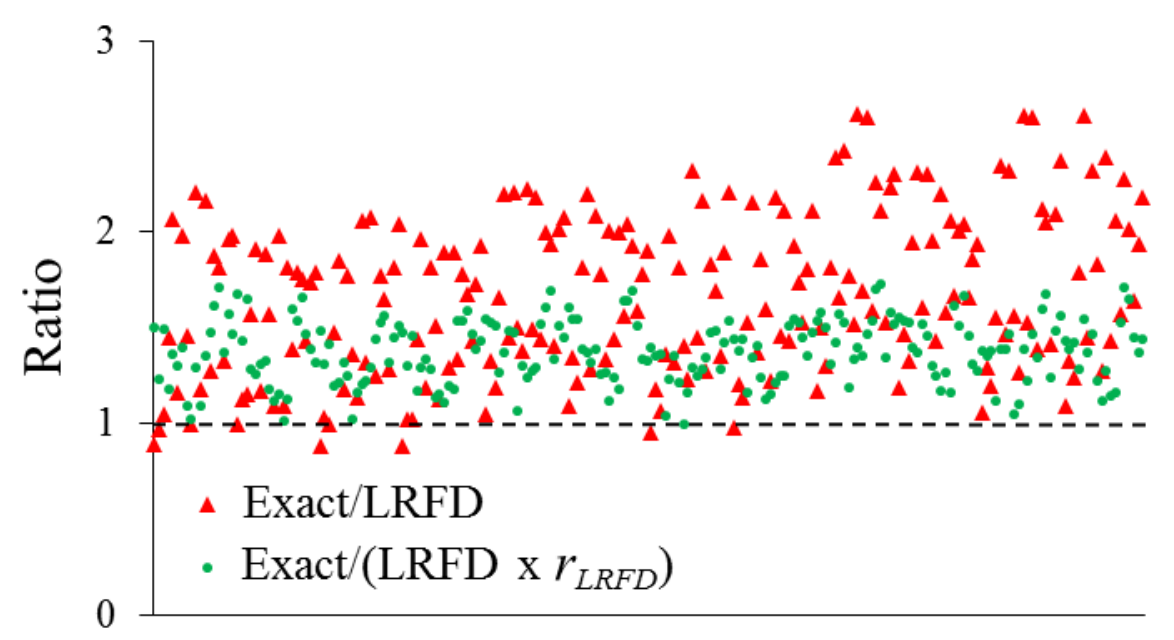

Fig. 1. Comparison of shear capacity ratios

822 


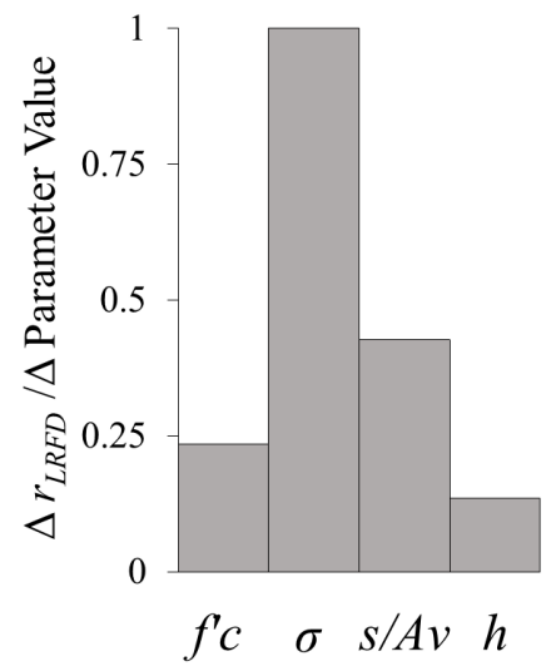

Fig. 2. Normalized sensitivity results of shear resistance variables

825
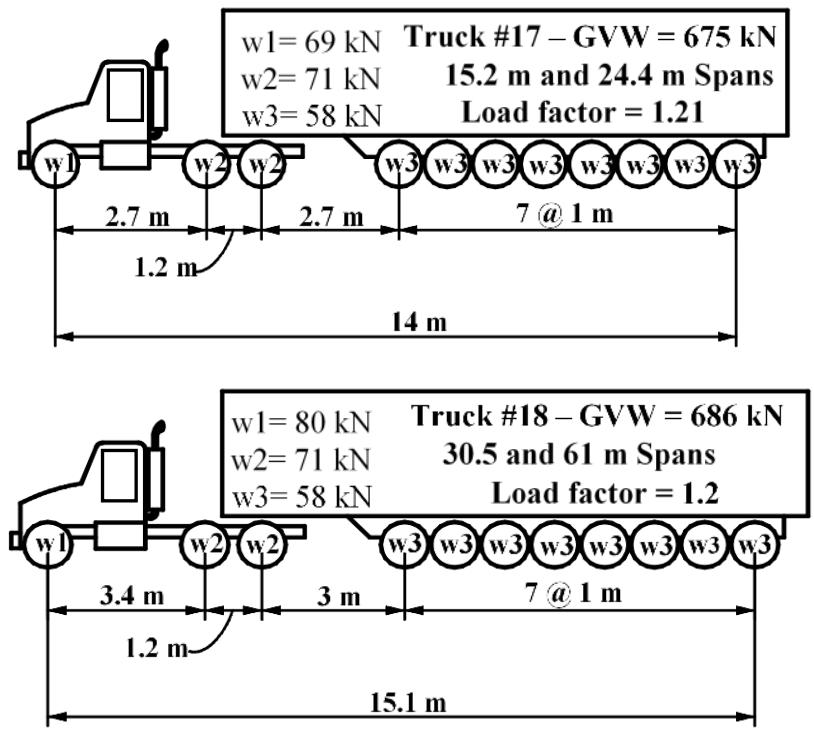

827 Fig. 3. MDOT governing legal trucks considered for reliability analysis (data from MDOT 2009) 

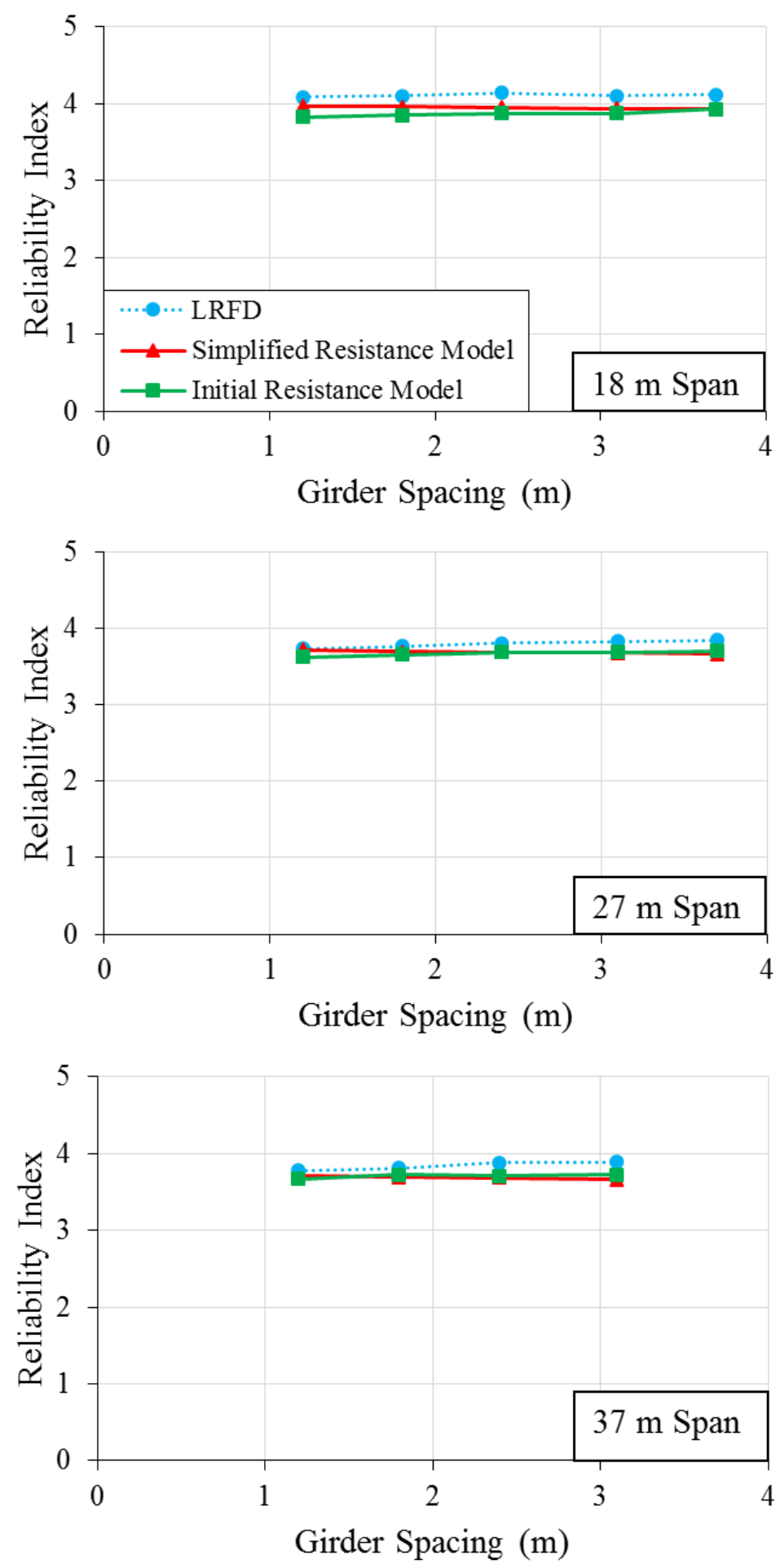

Fig. 4. Reliability indices for typical PC girders using AASHTO LRFD load models 832 


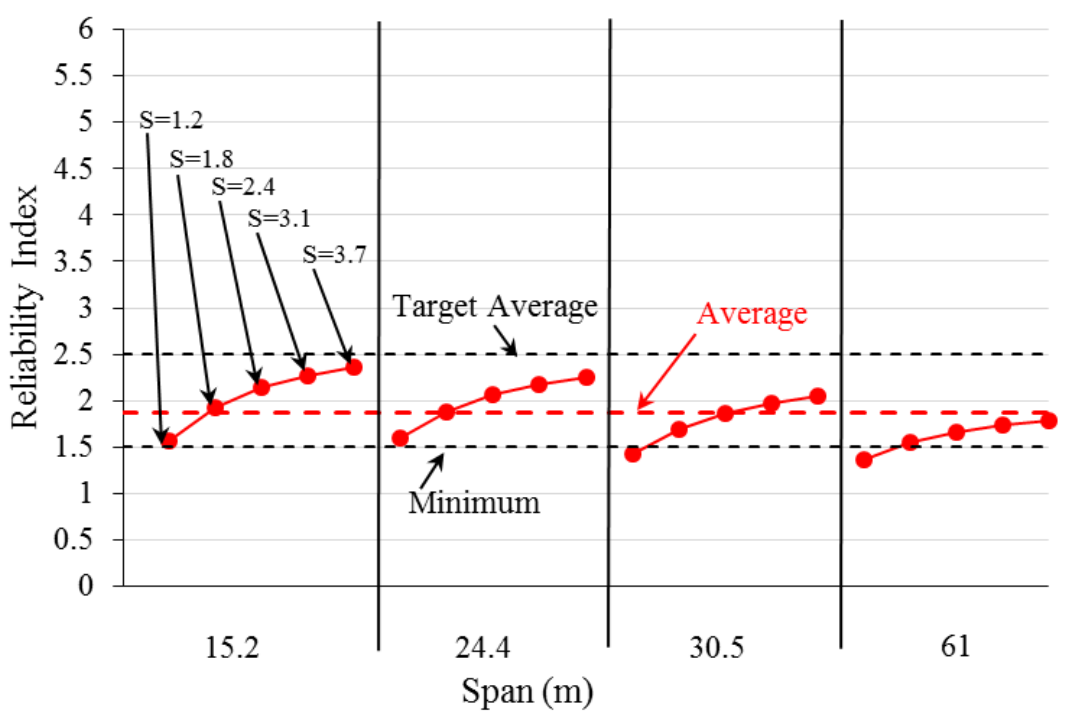

844

845

Fig. 5. Reliability indices for shear based on Michigan traffic loads and Simplified Resistance Model

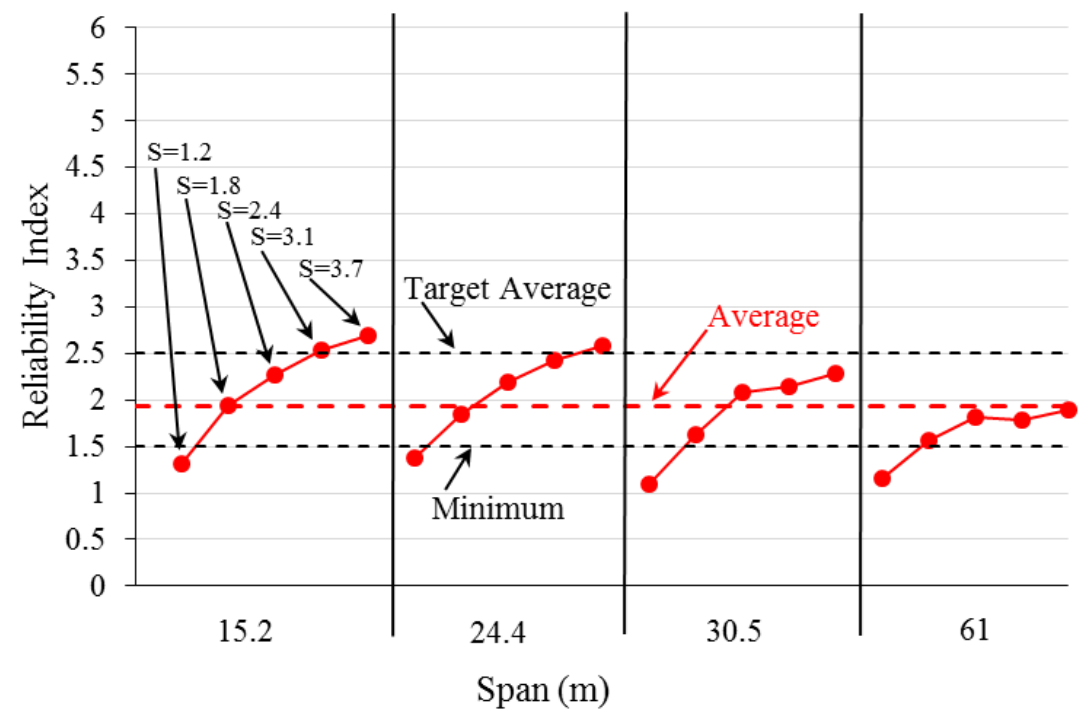

Fig. 6. Reliability indices for shear based on Michigan traffic loads and Initial Resistance Model 


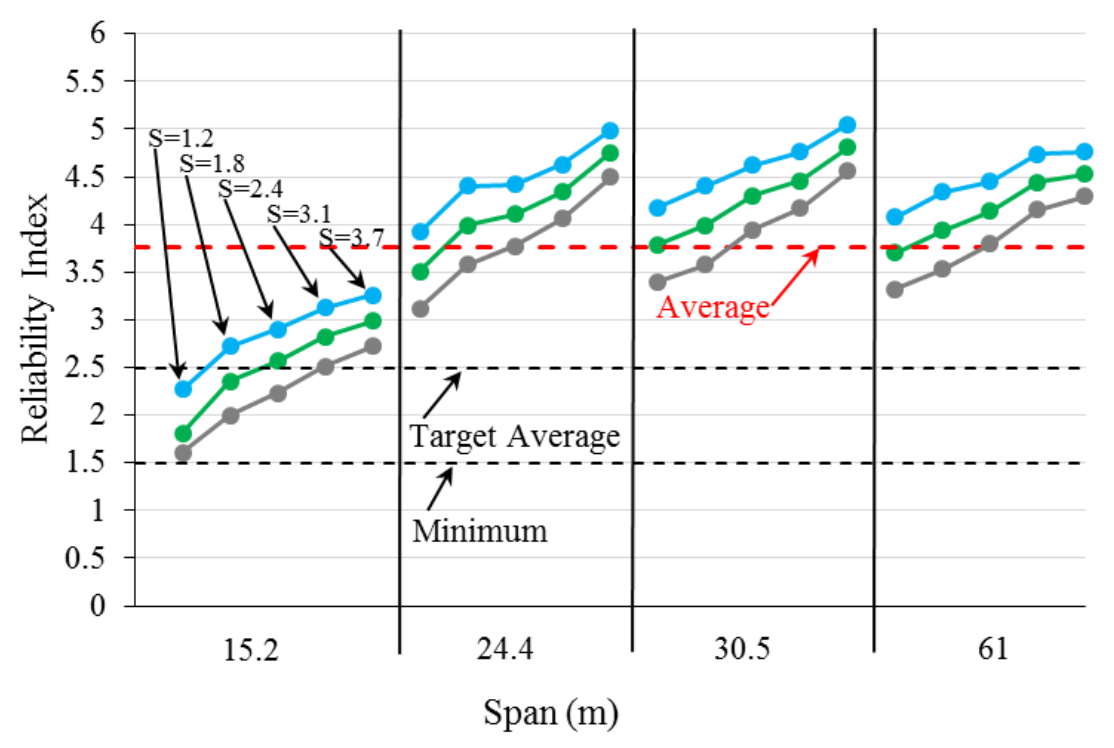

850

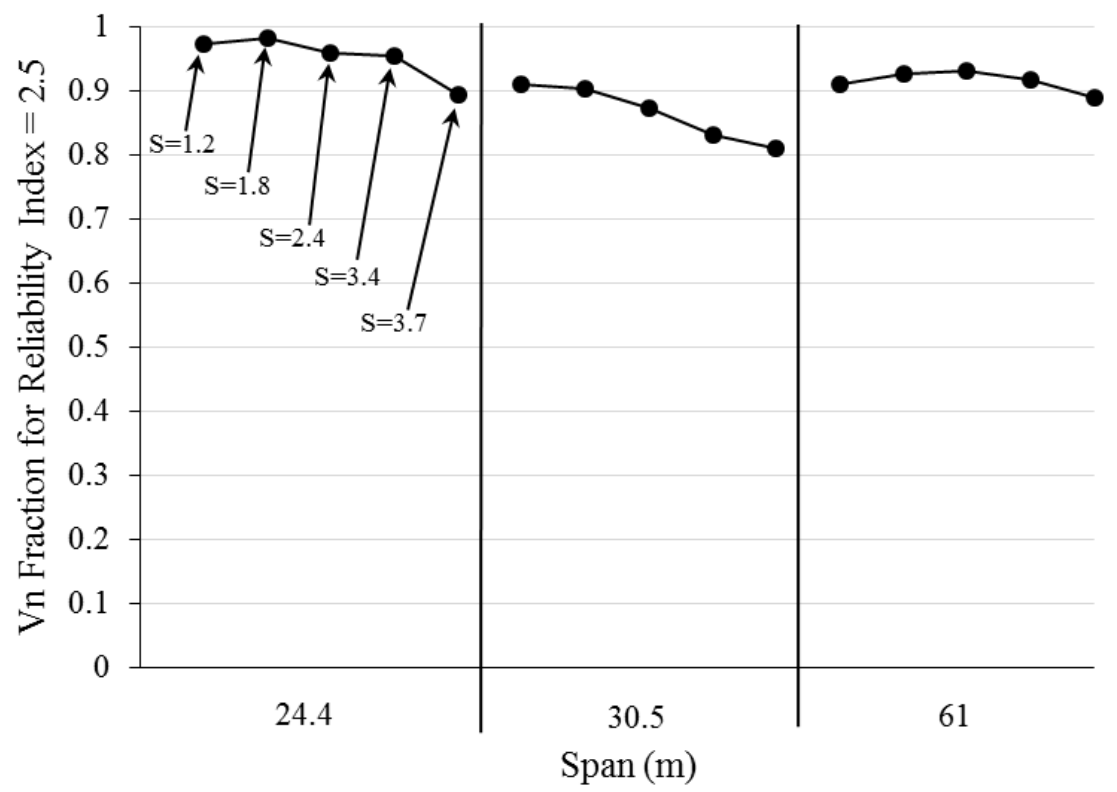

858

859

860

861

862

863 